\title{
Risk Of Suicide among Women Survived Domestic Violence In Erbil Governorate
}

\author{
Diana Aprem Kako; Department of Nursing, College of Nursing, Hawler Medical University, Erbil, Iraq. \\ Abdulqadir Hussen Gardi; Department of Nursing, College of Nursing, Hawler Medical University, Erbil, Iraq.
} (Correspondence: diana.kako@yahoo.com )

\begin{abstract}
Background and objectives: Domestic violence is a global issue leading to many medical and mental health consequences. A stable family relationship is mandatory for physical and mental health. The current study aimed at assessing the risk of suicide as a consequence of domestic violence among the survived women in Erbil governorate.

Methods: A cross-sectional study was conducted from 1st January 2018 to 31st December 2018. A sample of 105 women survived from domestic violence was recruited through a non-probability snowball sampling technique. Data were collected through direct interview with survivals using an adapted version of the ready-made questionnaire format of Columbia-Suicide Severity Rating Scale. The questionnaire was used for interviewing the women about (socio-demographic, violence, and risk of suicide). The validity and reliability of the instrument was checked. Data were analyzed by using the frequency, percentage and fisher exact test from the Statistical Package for Social Science version 23.

Results: The results of the study revealed that, the mean age of the study sample was 33.16 years old. $62.9 \%$ were married, and $63.8 \%$ were housewives. $33.3 \%$ of violence conducted was marital rape, in $26.2 \%$ of the cases; the violence was continuous throughout the past year. $76.2 \%$ of women wished for death and $57.1 \%$ thought of suicide. The suicidal risk was mostly linked to rape and sexual violence, were $100 \%$ of raped cases wished for death, and $62.5 \%$ of them had set a suicidal plan.

Conclusion: Domestic violence has a direct relation to the risk of suicide among women survived domestic violence.
\end{abstract}

Keywords: Suicide, Domestic-violence, Human, Female, Mental Health

\section{INTRODUCTION}

Violence against women is a serious human rights abuse and global public health issue. Women around the world are facing different forms of violence, such as physical, psychological, and sexual. The perpetrators could be strangers and/or family members who are known as domestic violence and intimate partner abuse [1]. Domestic violence is defined according to the department of justice of United States of
America (USA) as "a pattern of abusive behavior in any relationship that is used by one partner to gain or maintain power and control over another intimate partner". The act of violence could be physical, sexual, emotional, economic, or psychological actions or threats of actions that put a direct or indirect risk on the safety and security of another family member. This includes any behaviors that intimidate, manipulate, humiliate, isolate, frighten, 
terrorize, threaten, blame, hurt, injure, or wound someone within the context of family [2].

Throughout the history, violence against women was a private indoor matter. In fact, women beating were legal to some extent under the justification of disciplining. It wasn't until 1911 when the first court in the USA was established with the goal of solving domestic problems, that wife beating was made illegal in all states of the United States by 1920.

The women's movement of the 1960's and the anti-rape movement of the 1970's encouraged survivors of domestic violence to report, which led to the formation of women's crisis centers and hotlines [3].

In the Kurdistan Region of Iraq (KRG) the parliament passed the act of combating domestic violence in 2011 [4].

Such act of violence increases the risk for mental health disorder among survivals. Multiple studies have been conducted about domestic violence and its effect on mental and physical health, in all of the studies, results indicated that intimate partner violence is a factor contributing to mental disorders [5].

"Mental disorder is a syndrome characterized by a clinically significant disturbance in an individual's cognition, emotion regulation, or behavior that reflects a dysfunction in the psychological, biological, or developmental processes underlying mental functioning" [6].

Women who survive domestic violence incur $\$ 4.1$ billion per year in direct costs for medical and mental health services [7].

Globally domestic violence is also contributing to women's mortality through suicide including in Egypt (61\%), Brazil (48\%), India (64\%), Indonesia (11\%), and in the Philippines $(28 \%)$ of women had a significant correlation between domestic violence and suicidal ideation [8]. In the Kurdistan Region of Iraq (KRG) in the first 10 months of 2017, 20 suicide cases were reported which had a direct link to domestic violence [9].

Mental disorders are usually associated with significant distress in social, occupational, and other important activities [10]. According to World Health Organization (WHO), women survived from domestic violence are suffering from emotional distress, and survivals are in a higher risk for suicide comparing to other women [11]. WHO also reported that women are more victims of domestic violence then strangers' violence, and the lifetime prevalence of physical or sexual partner violence, or both, varied from (15\%) to $(71 \%)$ [1].

The main objective of this study was to assess the risk of suicide as a consequence of domestic violence among the survived women.

\section{METHODS}

A cross-sectional study was conducted among women survived from domestic violence to find the risk of suicide as a consequence of domestic violence among the survived women.

Duration of the study was from 1st January 2018 to 31st December 2018 in different locations in Erbil governorate. The study sample were 105 women survived from domestic violence, they were selected via using the snowball sampling technique to establish a representative sample of the targeted population, according to the study's inclusion and exclusion criteria; women and girls who aged equal and more than 18 years old were included based on their informed consent.

Data were collected from women safe spaces which are specialized for providing psychological support for women, and also part of data were collected from women shelter. Selected women were not diagnosed with any mental disorders before 
the occurrence of violence, and they had not been through any other accidents such as fire, traffic, terrorist, and robbery attack. The sample size was estimated based on the formula of. In which is standard normal variety at $5 \%$ type one error when proportion with a $95 \%$ level of confidence and a margin of error of $5 \%,=1.96$. $p$-value $<0.05$. The $d$ is the absolute error and it's equal to 0.05 . And $p$ stands for the expected portion of population based on published data, in the current study, as there is no formal published percentage of domestic violence cases in Erbil, the investigator calculated percentage of domestic violence cases based on report of WHO were they stated that 1 in 3 women are affected by domestic violence, thus referring to proportion of women in Erbil population, which is 466803 [12], and assuming that 1 in 3 women are affected by violence, Thus the $p=33.3 \%$. Referring to this equation; the total estimated study sample was (339) cases [14], [13].

Referring to the sensitivity and social stigma of domestic violence, lack of reporting, and time limitation; the investigator could reach only to 105 cases.

A pilot study on 15 cases was carried out for obtaining the "inter-rater reliability test. Internal consistency of the study was obtained through applying Pearson correlation $(r)$ which was (0.92); it indicates that there is a strong positive correlation. Direct face to face interview through questionnaire was conducted by the authors, after obtaining verbal consent from the study sample.

The data collection tool was modified from the ready-made questionnaire and expert recommendation. The questionnaire consisted of three parts. The first part was on socio-demographic characteristics of Study Sample. This part composed questions about the age of the participants, the marital status, and level of education, location, and occupation.

The second part assessed the types and forms of violence, were participants been asked about the form of violence whether it is physical violence which includes beating, burning, hair pulling, and any other violent act that have a negative impact on the body; Or sexual violence which is defined by WHO as "any sexual act, attempt to obtain a sexual act, unwanted sexual comments or advances, or acts to traffic, or otherwise directed, against a person's sexuality using coercion, by any person regardless of their relationship to the victim, in any setting, including but not limited to home and work" [1].

The psychological and emotional violence, which includes the acts or threats of acts resulting in emotional and psychological disturbance of the survivals.

Marital rape which is a rape conducted by the intimate partner. And the last type of violence which is financial abuse was the violence is been conducted by preventing the survivals to access their financial rights, or when the survival financial income is taken off by the perpetrator.

The frequency of violence act was assessed during the last year, either is contentious or been in certain point of time such as weekly or monthly, or whether the violence occurred only once during the previous year.

The last part of the questionnaire assessed the level and severity of suicide risk, which has been adopted from the ColumbiaSuicide Severity Rating Scale (C-SSRS).

The scale contains six questions about participant's thoughts, action, and feeling in the past month, with yes or no answer for each question, determining the stage of suicide risk that may be suicidal wishes, thoughts, intentions, plans, and suicidal behaviors [15].

The questionnaire was validated through a panel of experts from different scientific 
backgrounds related to nursing and medicine. The expert responses were based on agreement or disagreement with items of the questionnaire. The experts agreed to the contents of the questionnaire with some modifications regarding the biographic part and the expert also added more detail in the violence part. The investigator took into consideration their comments and prepared the final version of the questionnaire accordingly.

Prior to data collection, the formal permission was obtained from the ethical committee at the College of Nursing, Hawler Medical University. Furthermore, the informed oral consent was taken from the candidate who participated in the study, after confirmation of confidentiality, anonymity and participants self-determination by the researcher. Formal permission was also obtained from the Directorate of labor and social affairs and Directorate of women correctional center.

After data collection, the Statistical Package for Social Science (SPSS, Version 23) was used for data processing and statistical analysis. The statistical analysis included descriptive statistical analysis such as frequency and percentage to describe the basic features of the data in a study and provide simple summaries about the sample and the measures. Inferential statistical analyses as Chi-square and fisher exact test were implemented to make judgment about inferences from our data to more general conditions. The confidence interval was $95 \%$. The P-value of each test $\leq 0.05$ considered as statistically significant.

\section{RESULTS}

Table 1 shows the general sociodemographic characteristics of the study sample, the age of participants ranged from 18-59 years old, with the mean age of 33.16 years old. Regarding the marital status of the survivals, the highest percentage
(62.9\%) were married, while divorced and single were $14.3 \%$ and $13.3 \%$ respectively. The education level of participants showed that the highest percentage (40\%) was secondary school graduated and the percentage of the institute and/or college graduated was $30.5 \%$. As for the occupation, the highest percentages of the women (63.8\%) were housewives and $13.3 \%$ had semiskilled manual occupations. For the residency of participants; the results showed that $80 \%$ of survivals were living in urban areas.

Table 1: Socio-demographic characteristics of the survived females of domestic violence

\begin{tabular}{|c|c|}
\hline Characteristics $(n=105)$ & $\begin{array}{c}\text { Frequency } \\
\text { Distribution }\end{array}$ \\
\hline \multirow[t]{2}{*}{ Age (year) Range: 18-59 } & $\begin{array}{c}\text { Mean } \pm \text { St. } \\
\text { Deviation } \\
33.16 \pm 9.28\end{array}$ \\
\hline & $F(\%)$ \\
\hline \multicolumn{2}{|l|}{ Marital Status } \\
\hline Single & $14(13.3)$ \\
\hline Married & $66(62.9)$ \\
\hline Divorced & $15(14.3)$ \\
\hline Widowed & $7(6.7)$ \\
\hline Separated & $3(2.9)$ \\
\hline \multicolumn{2}{|l|}{ Education } \\
\hline Illiterate & $7(6.7)$ \\
\hline Read and write & $12(11.4)$ \\
\hline Primary school graduate & $8(7.6)$ \\
\hline Secondary school graduate & $42(40)$ \\
\hline Institute/college & $32(30.5)$ \\
\hline Postgraduate & $4(3.8)$ \\
\hline \multicolumn{2}{|l|}{ Occupation } \\
\hline Associate professional occupations & $4(3.8)$ \\
\hline Skilled manual and non-manual & $3(2.9)$ \\
\hline occupation & $14(13.3)$ \\
\hline Semi-skilled manual occupations & $5(4.8)$ \\
\hline Unskilled manual occupations & $67(63.8)$ \\
\hline House wife & $12(11.4)$ \\
\hline \multicolumn{2}{|l|}{ Student } \\
\hline \multicolumn{2}{|l|}{ Residential area } \\
\hline Urban & $84(80)$ \\
\hline Rural & $21(20)$ \\
\hline
\end{tabular}


Regarding the type of violence; as it shows in the table 2; the result shows that most common type of violence conducted (33.3\%) was marital rape. Physical violence and emotional violence come in the second and third place with the percentage of $26.7 \%$ and $21.9 \%$. The study results of recurrence of violence in past year indicated that the violent act was continuous in $36.2 \%$ of the cases while $20 \%$ of participants were subjected to violence once per month. Regarding the perpetrator; the violent act was conducted by the intimate partner in the most of cases $(70.5 \%)$.

Table 2: Forms of domestic violence among survived females of violence.

\begin{tabular}{lc}
\hline \multirow{2}{*}{$\begin{array}{l}\text { Violence characteristics } \\
\text { (n=105) }\end{array}$} & $\begin{array}{c}\text { Frequency Distribu- } \\
\text { tion }\end{array}$ \\
\cline { 2 - 2 } $\begin{array}{l}\text { Violence type } \\
\text { Physical violence }\end{array}$ \\
Sexual Violence & $28(26.7)$ \\
Emotional Violence & $6(5.7)$ \\
Rape & $23(21.9)$ \\
Marital rape & $8(7.6)$ \\
Financial abuse & $35(33.3)$ \\
Frequency of violence & $5(4.8)$ \\
Continuous & \\
once per week & $38(36.2)$ \\
1/month & $20(19)$ \\
1/3months & $21(20)$ \\
1 / 6 months & $5(4.8)$ \\
1/ year & $6(5.7)$ \\
Violence Perpetrator & $15(14.3)$ \\
Intimate partner & \\
Brother & $54(70.5)$ \\
Father & $5(4.8)$ \\
Second degree relative & \\
Children & \\
\hline
\end{tabular}

Table 3 shows different level of suicide risk; were the results indicated that, most of the participants (76.2\%) wished for death, while $57.1 \%$ of participants had suicidal thoughts without any suicidal plans. $35.2 \%$ of the study, sample thought of suicide in addition to setting a special suicidal plan meanwhile more than half of the participants $(64.8 \%)$ did not plan for the suicide. Suicide attempt was positive in $17.1 \%$ of the participants.

Table 3: Suicide risk assessment among women survived domestic violence

\begin{tabular}{lc}
\hline \multirow{2}{*}{ Depressive disorders } & \multicolumn{1}{c}{ Frequency Distribution } \\
\cline { 2 - 2 } Death wish & \\
Yes & \\
No & $80(76.2)$ \\
Suicidal Thought & $25(23.8)$ \\
Yes & \\
No & $60(57.1)$ \\
Thought Plan & $45(42.9)$ \\
Yes & \\
No & $37(35.2)$ \\
Suicidal Behavior & $68(64.8)$ \\
Yes & \\
No & $18(17.1)$ \\
\hline
\end{tabular}

Regarding the association between the perpetrator and risk of suicide, as it shown in the table 4, result revealed that majority of cases $(71.3 \%)$ who survived from violence conducted by their intimate partner, wished for death; the results were statistically significant with $p$-value $=0.01$. Results also demonstrate a significant relationship between perpetrator and suicidal thoughts, were $70 \%$ of survivors from 
intimate partner violence had active suicidal thoughts, with $p$-value $=0.01$. Regarding active suicidal thought with suicidal plan, however generally most of the cases didn't have specific suicidal plan, yet $62.2 \%$ of cases who faced violence from their intimate partner had set a specific suicidal plan, the relation were statistically significant with $p$-value $=0.01$.

Table 4: Association between perpetrator and risk of suicide

\begin{tabular}{|c|c|c|c|c|c|}
\hline Risk of suicide & $\begin{array}{c}\text { Intimate partner } \\
\qquad(\%) \\
\end{array}$ & $\begin{array}{c}\text { Brother } \\
\text { F (\%) }\end{array}$ & $\begin{array}{c}\text { Father } \\
\text { F (\%) } \\
\end{array}$ & $\begin{array}{c}\text { Second degree relative } \\
\qquad \mathrm{F}(\%) \\
\end{array}$ & P-value * \\
\hline \multicolumn{6}{|l|}{ Dead Wish } \\
\hline Yes & $57(71.3)$ & $1(1.3)$ & $7(8.8)$ & $15(18.8)$ & \multirow[t]{2}{*}{$0.013^{* *}$} \\
\hline No & $17(68)$ & $4(16)$ & $3(12)$ & $1(4)$ & \\
\hline \multicolumn{6}{|l|}{ Suicidal though } \\
\hline Yes & $42(70)$ & $0(0.0)$ & $6(10)$ & $12(20)$ & \multirow[t]{2}{*}{$0.013^{* *}$} \\
\hline No & $32(71.1)$ & $5(11.1)$ & $4(8.9)$ & $4(8.9)$ & \\
\hline \multicolumn{6}{|l|}{ Suicidal Plan } \\
\hline Yes & $23(62.2)$ & $0(0.0)$ & $4(10.8)$ & $10(27)$ & \multirow{2}{*}{$0.019 * *$} \\
\hline No & $51(75)$ & $5(7.4)$ & $6(8.8)$ & $6(8.8)$ & \\
\hline \multicolumn{6}{|l|}{ Suicidal Behavior } \\
\hline Yes & $12(66.7)$ & $0(0.0)$ & $4(22.2)$ & $2(11.1)$ & \multirow[t]{2}{*}{$0.165^{* * *}$} \\
\hline No & $62(71.3)$ & $5(5.7)$ & $6(6.9)$ & $14(16.1)$ & \\
\hline \multicolumn{6}{|c|}{ *Fishers' Exact test was performed for statistical analysis, ${ }^{* *}$ significant, ${ }^{* * *}$ non-significant } \\
\hline \multicolumn{3}{|c|}{$\begin{array}{l}\text { As for the association between risk of sui- } \\
\text { cide and type of violence, result showed } \\
\text { that } 40 \% \text { of women who were raped by } \\
\text { their spouse, wished for death and also } \\
\text { had thought of suicide, the result was high- } \\
\text { ly significant with p-value }=0.001 \text {. Regard- } \\
\text { ing the active suicidal thoughts with plans, }\end{array}$} & \multicolumn{3}{|c|}{$\begin{array}{l}\text { who survived marital rape and } 24.3 \% \text { of } \\
\text { physical violence survivals had set suicidal } \\
\text { plan. Results were considered statistically } \\
\text { significant with p-value }=0.03 \text {. Regarding } \\
\text { suicidal behaviors, while } 50 \% \text { marital raped } \\
\text { women had suicidal behavior, the relation- } \\
\text { ship was statistically non-significant. }\end{array}$} \\
\hline
\end{tabular}
table 5 revealed that, $37.8 \%$ of women

Table 5: Association between different types of domestic violence and risk of suicide

\begin{tabular}{|c|c|c|c|c|c|c|c|}
\hline \multirow[b]{2}{*}{ Risk of suicide } & \multicolumn{6}{|c|}{ Violence Types } & \multirow[b]{2}{*}{ P-value * } \\
\hline & $\begin{array}{c}\text { Physical } \\
\text { violence } \\
\text { F (\%) }\end{array}$ & $\begin{array}{c}\text { Sexual } \\
\text { Violence } \\
\text { F (\%) }\end{array}$ & $\begin{array}{c}\text { Emotional } \\
\text { Violence } \\
F(\%)\end{array}$ & $\begin{array}{l}\text { Rape } \\
\text { F (\%) }\end{array}$ & $\begin{array}{c}\text { Marital } \\
\text { rape } \\
\text { F (\%) }\end{array}$ & $\begin{array}{c}\text { Financial } \\
\text { abuse } \\
\text { F (\%) }\end{array}$ & \\
\hline $\begin{array}{c}\text { Death Wish } \\
\text { Yes } \\
\text { No }\end{array}$ & $\begin{array}{c}15(18.7) \\
13(52)\end{array}$ & $\begin{array}{l}6(7.5) \\
0(0.0)\end{array}$ & $\begin{array}{c}16(20) \\
7(28)\end{array}$ & $\begin{array}{l}8(10) \\
0(0.0)\end{array}$ & $\begin{array}{c}32(40) \\
3(12)\end{array}$ & $\begin{array}{c}3(3.8) \\
2(8)\end{array}$ & $0.001 * *$ \\
\hline $\begin{array}{c}\text { Suicidal thoughts } \\
\text { Yes } \\
\text { No }\end{array}$ & $\begin{array}{l}11(18.2) \\
17(37.8)\end{array}$ & $\begin{array}{l}6(10) \\
0(0.0)\end{array}$ & $\begin{array}{c}14(23.3) \\
9(20)\end{array}$ & $\begin{array}{l}5(8.3) \\
3(6.7)\end{array}$ & $\begin{array}{c}24(40) \\
11(24.4)\end{array}$ & $\begin{array}{c}0(0.0) \\
5(11.1)\end{array}$ & $0.001^{* *}$ \\
\hline $\begin{array}{c}\text { Suicidal Plan } \\
\text { Yes } \\
\text { No }\end{array}$ & $\begin{array}{c}9(24.3) \\
19(27.9)\end{array}$ & $\begin{array}{c}4(10.8) \\
2(2.9)\end{array}$ & $\begin{array}{c}5(13.5) \\
18(26.5)\end{array}$ & $\begin{array}{c}5(13.5) \\
3(4.4)\end{array}$ & $\begin{array}{l}14(37.8) \\
21(30.9)\end{array}$ & $\begin{array}{l}0(0.0) \\
5(7.4)\end{array}$ & $0.039 * * *$ \\
\hline $\begin{array}{c}\text { Suicidal behavior } \\
\text { Yes } \\
\text { No }\end{array}$ & $\begin{array}{r}3(16.7) \\
25(26.7)\end{array}$ & $\begin{array}{l}0(0.0) \\
6(6.9)\end{array}$ & $\begin{array}{c}4(22.2) \\
19(21.8)\end{array}$ & $\begin{array}{c}2(11.1) \\
6(6.9)\end{array}$ & $\begin{array}{c}9(50) \\
26(29.9)\end{array}$ & $\begin{array}{l}0(0.0) \\
5(5.7)\end{array}$ & $0.222 * * * *$ \\
\hline
\end{tabular}

*Fishers' Exact test was performed for statistical analyses. ${ }^{* *}$ highly significant $* * * *$ significant $* * * *$ non-significant 


\section{DISCUSSION}

The aim of the current study was to assess the risk of suicide among women survived domestic violence. Regarding the sociodemographic characteristics, the highest percentage of the study sample was in their age of thirties, Mean \pm SD of participant's age was $33.16 \pm 9.28$, minimum age 18 years old and maximum age 59 years old. Most of them were married, and they were mostly secondary school graduated, and the majority of the study samples were housewives and they were living in urban areas. These results were similar to the findings of a study conducted in KRG by AlAtrushi et al, as they also found that majority of women suffering from domestic violence are in between 25-34 years old [16], and also according to the WHO multicountry study on women's health and domestic violence, results showed that (13\%) to $(61 \%)$ of women who reported on domestic violence are between 15 and 49 years old [11]. Regarding educational background, the results indicated that the violence has mostly occurred among women who had less degree of formal education. Results of the current study were similar to a study conducted in Erbil by Namir AlTawil, about the association of violence against women with religion and culture in Erbil Iraq, were only half of the participants (50.4\%) had more than 12 years of formal education [17]. Women who are less educated usually have less knowledge about the law, and they are less independent financially as most of them are housewives, thus it's make them an easier target of violence because they don't ask for their rights. Results were also supported by a study conducted in USA, on the risk factors for Intimate Partner Violence (IPV), were they reported that having a school degree of less than high school will increase the risk of IPV [18].
Regarding the type of violence conducted against the study sample, the heights percentage (33.3\%) was marital rape which is forcing the partner on sexual intercourse. Similar findings of sexual violence by the intimate partner were reported in Erbil $12.1 \%$ [16], $42.2 \%$ in Iran [19], $16.4 \%$ in Spain [20], and $12 \%$ in China [21]. Such a high percentage of intimate partner sexual violence could be linked to the social and cultural norms were in most contexts marital rape is not recognized as a violation of women rights. Men and to some extent women believe that the intimate partner has the right of sexual intercourse at any time, and the wife is not to refuse or object.

In most of the cases (36.2\%) the violence was continuous in the past year, which means the survived women were living in a stressful situation most of their time, and also the violence could happen during pregnancy and in front of their children. Regarding the perpetrator; violence was mostly conducted by an intimate partner (70\%), these results were also reported by WHO, as they found that most of the violence faced by women are committed by their intimate partner, WHO also reported that; worldwide, almost one third (30\%) of women who have been in a relationship report that they have experienced some form of physical and/or sexual violence by their intimate partner in their lifetime [13]. Regarding the risk of suicide; results of this study revealed that generally there is a high risk of suicide among women survived from domestic violence, the majority of the study sample $(76.2 \%)$ wished that they were dead. $57.1 \%$ of them randomly thought of suicide and imagined their death, but they had no actual suicidal plan. Meanwhile $35.2 \%$ of survivals thought of suicide and had a suicidal plan and they were thinking of implementing the suicidal plan, among them $17.1 \%$ attempted for 
suicide or arranged everything for suicide but changed their mind in the last minute before acting the plan. Globally domestic violence was found to be a risk factor for suicide in women. In KRG in the first 10 months of 2017, 20 suicide cases were reported which had a direct link to domestic violence [9].

Referring to a study published in Indian Journal of Psychiatry in 2015; results showed a significant relationship between domestic violence and suicidal ideations, in Egypt 61\%, Brazil 48\%, India 64\%, Indonesia $11 \%$, and in the Philippines $28 \%$ of women who had suicide ideation, it was due to domestic violence problems [8]. Davis (2010), reported that approximately $30 \%$ of suicides in 16 states of the USA in 2005 were precipitated by intimate partner problems [22].

As for the association between type of violence and different level of suicide, results demonstrate that wishing for death were mostly associated with survivors who experienced marital rape, and this is usually related to the social stigma that women and girls are facing when they goes through such experience, as marital rape is not recognized as violence; in some cases the survivors are looking at as the main guilty person and they may face the risk of divorce or physical violence if they reject such violence by their spouse, were women are expecting protection and affection from their intimate partner, such act of violence by the intimate partner will cause extreme depression and emotional disturbance to the women leading to suicidal thoughts. Living in an environment where same violence act is repeated many times is very likely to create frustration leading to suicidal plan as it occurred in $37.8 \%$ of marital rape survived women. Kilpatrick (2000), found that $33 \%$ of the rape survivals have thought of suicide, and they were 4.1 times more likely than non-crime victims to have contemplated suicide, and rape victims were also 13 times more likely to have attempted suicide [23].

\section{CONCLUSION}

Domestic violence has a direct link to the deterioration of mental health; women survived from domestic violence are at high risk of suicide due to the violence that they face. Domestic violence is always seen as a private family issue, were reporting against violence act will put the survival in risk of social stigma and also the risk of honor killing by family members, which increase the stress on the survivals, leading to depression and eventually put the survivals at a higher risk of suicide.

\section{CONFLICTS OF INTEREST}

The authors have no any conflict of interest

\section{REFERENCES}

[1] Garcia-Moreno C, Jansen HAFM, Ellsberg M, Heise L, Watts CH, WHO Multi-country Study on Women's Health and Domestic Violence against Women. Lancet London England. 2006 7;368 (9543):1260_9. Available from: https://www.ncbi.nlm.nih.gov/ pubmed/17027732 [Accessed 19th July 2018].

[2] The United States department of justices. Domestic Violence. 2017. Available from: https://www.justice.gov/ovw/domesticviolence[Accessed 19th May 2018].

[3] Orloff LE, Feldman P. Domestic Violence and Sexual Assault Public Policy Timeline Highlighting Accomplishments on Behalf Of Immigrants and Women of Color. National Immigrant Women's Advocacy Project; 2017. Available from: http://library.niwap.org/wpcontent/uploads/Herstory-2016.pdf [Accessed 23th Feb 2018].

[4] Parliament of Kurdistan. The act of combating domestic violence in Kurdistan region -Iraq 2011. Available from: http:// www.ekrg.org/files/pdf/ combat_domestic_violence_english.pdf [Accessed 10th October 2017]. 
[5] Campbell JC. Health consequences of intimate partner violence. The Lancet. $2002 \mathrm{Apr}$ 13;359 (9314):1331-6. Available from: http://opendoorsproject.ca/wp-content/ uploads/2016/06/Campbell-2002-Healthconsequences-of-int-partner-violence-1.pdf [Accessed 13th March 2018].

[6] Heugten D.V - van der Kloet D and Heugten V. T. The classification of psychiatric disorders according to DSM-5 deserves an internationally standardized psychological test battery on symptom level. Frontiers in Psychology. 2015. 6:1108. doi: 10.3389/ fpsyg.2015.01108. Available from: https:// www.ncbi.nlm.nih.gov/pmc/articles/ PMC4523712/ [Accessed 4th Aug 2018].

[7] Carrell SE, Hoekstra M. Family Business or Social Problem? The Cost of Unreported Domestic Violence. 2011. Available from: http://faculty.econ.ucdavis.edu/faculty/ scarrell/reporting.pdf [Accessed 12th July 2018].

[8] Vijayakumar L. Suicide in women. Indian Journal of Psychiatry. 2015 Jul;57:(6):233-8. Available from: http:// www.indianjpsychiatry.org/article.asp? issn $=0019$ -

5545; year $=2015$; volume $=57$; issue $=6$; spage $=2$ 33; epage=238; aulast=Vijayakumar [Accessed 4th Aug 2018].

[9] Directorate of combating violence against women. Statistics of violence against women in 2017. 2017. Available from: http:// bgtakrg.org/index.php/statics/item/8302017 [Accessed 4th Nov 2017].

[10] Maisel ER. The New Definition of a Mental Disorder. 2013. Available from: http:// www.psychologytoday.com/blog/rethinkingmental-health/201307/the-new-definitionmental-disorder [Accessed 10th October 2017].

[11] World Health Organization. WHO multicountry study on women's health and domestic violence against women. 2005. Available from: http:// apps.who.intirisbitstream/10665/43310/1/9 241593512_eng.pdf [Accessed 12th July 2018].

[12] World population review. Population of Cities in Iraq.2018. Available from: http:// worldpopulationreview.com/countries/iraqpopulation/cities/ [Accessed 14th July 2018].
[13] World Health Organization. Violence against women. 2017. Available from: http:// www.who.int/news-room/fact-sheets/ detail/violence-against-women [Accessed 27th Aug 2018].

[14] Charan J, Biswas T. How to Calculate Sample Size for Different Study Designs in Medical Research? Indian Journal of Psychological Medicine. 2013;35 (2):121-6. Available from: https://www.ncbi.nlm.nih.gov/pmc/ articles/PMC3775042/ [Accessed 12th Oct 2017].

[15] Posner K, Brent D, Lucas C, Gould M, Stanley $\mathrm{B}$, Brown G, et al. Columbia-suicide severity rating scale (C-SSRS). 2008. Available from: http://cssrs.columbia.edu/wp-content/ uploads/C-SSRS1-14-09-Screening.pdf [Accessed 27th Oct 2017].

[16] Al-Atrushi HH, Al-Tawil NG, Shabila NP, AlHadithi TS. Intimate partner violence against women in the Erbil city of the Kurdistan region, Iraq. BMC Women's Health. 2013 Oct 10;13:37. Available from: https:// www.ncbi.nlm.nih.gov/pmc/articles/ PMC3852841/ [Accessed 12th Oct 2017].

[17] Al-Tawil NG. Association of violence against women with religion and culture in Erbil Iraq: a cross-sectional study. BMC Public Health. 2012 Sep 17;12:800. Available from: https://

bmcpublichealth.biomedcentral.com/ articles/10.1186/1471-2458-12-800

[Accessed 12th Oct 2017].

[18] Walton-Moss BJ, Manganello J, Frye V, Campbell JC. Risk Factors for Intimate Partner Violence and Associated Injury Among Urban Women. Journal of Community Health. 2005 Oct 1;30(5):377-89. Available from: https://www.ncbi.nlm.nih.gov/ pubmed/16175959 [Accessed 3d July 2018].

[19] Aghlmand S, Akbari F, Lameei A, Mohammad K, Small R, Arab M. Developing evidencebased maternity care in Iran: a quality improvement study. BMC Pregnancy Childbirth. 2008;8:20. Available from: https:// www.ncbi.nlm.nih.gov/pmc/articles/ PMC2443790/ [Accessed 3d July 2018].

[20] Pico-Alfonso MA, Garcia-Linares MI, CeldaNavarro N, Blasco-Ros C, Echeburúa E, Martinez M. The impact of physical, psychological, and sexual intimate male partner violence on women's mental health: depressive symptoms, posttraumatic stress disorder, state anxiety, and suicide. Journal of Women's Health. 2006 Jun;15(5):599-611. 
Available from: http://www.ehu.eus/ echeburua/pdfs/21-pico-alfonso_et_al.pdf [Accessed 14th May 2018].

[21] Xu X, Zhu F, O'Campo P, Koenig MA, Mock V, Campbell J. Prevalence of and Risk Factors for Intimate Partner Violence in China. American Journal of Public Health. 2005 Jan;95 (1):78-85. Available from: https:// www.ncbi.nlm.nih.gov/pmc/articles/ PMC1449856/ [Accessed 4th Aug 2018].

[22] Davis R. Domestic violence related deaths. 2010. Available from: http://mediaradar.org/ docs/DavisDomesticViolenceRelatedDeaths.pdf [Accessed 27th Aug 2018].

[23] Kilpatrick DG. Mental health impact of rape. 2000. Available from: https://mainwebv.musc.edu/vawprevention/research/ mentalimpact.shtml[Accessed 27th Aug 2018]. 